\title{
Higher intrinsic network excitability in ventral compared with the dorsal hippocampus is controlled less effectively by $\mathrm{GABA}_{\mathrm{B}}$ receptors
}

Costas Papatheodoropoulos ${ }^{*}$

\begin{abstract}
Background: Elucidating specializations of the intrinsic neuronal network between the dorsal and the ventral hippocampus is a recently emerging area of research that is expected to help us understand the mechanisms underlying large scale functional diversification along the hippocampus. The aim of this study was to characterize spontaneous network activity between the dorsal and the ventral hippocampus induced under conditions of partial or complete blockade of GABAergic inhibition (i.e. disinhibition).

Results: Using field recordings from the CA3 and CA1 fields of hippocampal slices from adult rats I found that ventral compared with dorsal hippocampus slices displayed higher propensity for and higher frequency of occurrence of spontaneous field potentials (spfps) at every level of disinhibition. Also NMDA receptor-depended spfps (spfps_nmda) occurred with higher probability more frequently and were larger in the ventral compared with the dorsal hippocampus. Importantly, blockade of $\mathrm{GABA}_{B}$ receptors produced a stronger effect in enhancing the probability of generation of spfps and spfps_nmda in the dorsal compared with the ventral hippocampal slices and increased spfps -nmda $_{\text {only in }}$ dorsal slices.

Conclusion: These results demonstrate a higher intrinsic neuronal excitability of the ventral compared with the dorsal local circuitry with the considerable contribution of NMDA receptors. Furthermore, the $G_{A B A}$ receptors control the total and the NMDA receptor-dependent excitation much less effectively in the ventral part of the hippocampus. It is proposed that NMDA and $\mathrm{GABA}_{B}$ receptors significantly contribute to differentiate local network dynamics between the dorsal and the ventral hippocampus with important implications in the information processing performed along the long hippocampal axis.
\end{abstract}

Keywords: Hippocampus, Septotemporal, Dorsoventral, Excitability, Inhibition, Disinhibition, Network, GABA receptor, $G_{A B A}$ receptor, NMDA receptor

\section{Background}

Local neuronal networks participate to brain functions by changing their excitability status through a dynamic modulation of the balance between excitation and inhibition [1]. The intrinsic hippocampal circuitry has been perceived as a model to understand the interactions

\footnotetext{
*Correspondence: cepapath@upatras.gr; cepapath@med.upatras.gr Laboratory of Physiology, Department of Medicine, School of Health Sciences, University of Patras, Rion, 26504 Patras, Greece
}

between the various components that control the excitation/inhibition balance in local circuitry. Continuous experimental work for decades has accumulated a great amount of information about the function of intrinsic neuronal circuitry of the hippocampus [2]. The internal circuitry of the hippocampus presents some very notable regularity, in that its fundamental structural organization is consisted of a local "trisynaptic" circuitry repeated along the long (dorsoventral or septotemporal) axis of the structure as a regular unit [3]. The longitudinal repetition 
of this "canonical module" has created the persistent view of the hippocampus as a structure with homogeneity along its dorsoventral course. For long time the idea of this dorsoventral internal homogeneity of the hippocampal circuitry has neglected early neurochemical and physiological evidence showing differences along the hippocampus [4-10]. Only recently the differences along the dorsoventral axis and especially between the $\mathrm{DH}$ and $\mathrm{VH}$ have been more systematically attracted the attention of researchers. For instance, differences between $\mathrm{DH}$ and $\mathrm{VH}$ have been revealed in the synaptic transmission and neurotransmitter receptors [11-14] as well as in the synaptic plasticity [15-18]. Yet, the first characteristic difference that was observed between the two hippocampal poles was the higher susceptibility of the ventral hippocampus in rodents and the anterior hippocampus in human to epileptic activities $[19,20]$. These early observations were repeatedly confirmed and extended by subsequent more thorough in vivo and in vitro studies performed in rats $[4,7,21-30]$. These studies led to the idea of the greater overall excitability of $\mathrm{VH}$ compared with DH. However, the mechanisms of apparent higher excitability of $\mathrm{VH}$ are still not well understood, perhaps because differences in network excitability arise from a combination of molecular, cellular and network mechanisms. GABAergic synaptic transmission constitutes a basic determinant of the local neuronal network excitability [31]. A typical experimental approach to study synchronous network activity is based on the induction of spontaneous activity in isolated brain preparations [32]. Classically, this is achieved by changing the excitation/ inhibition balance through lowering inhibitory activity using the so-called disinhibition models [33]. Indeed, GABAergic transmission could be a crucial factor in determining the threshold for excitation of the local circuit [34]. Paradoxically, however, the effects of blockade of GABAergic transmission on the spontaneous network activity have been never examined comparatively between $\mathrm{DH}$ and $\mathrm{VH}$. In the present study, I comparatively examined the ability of $\mathrm{DH}$ and $\mathrm{VH}$ to spontaneously generate population activity under conditions of partial or complete disinhibition using field recordings from transverse hippocampal slices. The results show that the intrinsic neuronal network of $\mathrm{VH}$ compared with DH exhibits higher excitability with the NMDA receptors having a significant contribution in the higher excitability of $\mathrm{VH}$. Furthermore, $\mathrm{GABA}_{\mathrm{B}}$ Rs play a more important role in restricting network excitability in $\mathrm{DH}$ than in $\mathrm{VH}$.

\section{Methods}

\section{Animals and slice preparation}

Forty-five adult (2-4 months old) male Wistar rats (Athens Pasteur Institute) were used in this study. Animals were obtained from the Animal Facility of the Medical School of the University of Patras. All experimental treatment and procedures were conducted in accordance with the European Communities Council Directive Guidelines (86/609/EEC, JL 358, 1, December, 12, 1987) for the care and use of Laboratory animals and they have been approved by the Prefectural Animal Care and Use Committee (No: EL 13BIO04). In addition, all efforts have been made to minimize the number and the suffering of animals used. Animals were housed in a room with a controlled light-dark cycle (12 h light-12 h dark) and free access to food and water. Slices from the two hippocampal poles were prepared as follows. The animals after deep anesthesia with diethyl ether were decapitated with a guillotine and their brain was removed and submerged in chilled $\left(2-4{ }^{\circ} \mathrm{C}\right)$ standard medium containing (in $\mathrm{mM}$ ): $124 \mathrm{NaCl} ; 4 \mathrm{KCl} ; 2 \mathrm{MgSO}_{4} ; 2 \mathrm{CaCl}_{2} ; 1.25$ $\mathrm{NaH}_{2} \mathrm{PO}_{4} ; 26 \mathrm{NaHCO}_{3} ; 10$ glucose; at pH 7.4, and the two hippocampi were excised free. Using a McIlwain tissue chopper, 500-550 $\mu \mathrm{m}$ thick slices, transverse to the long axis of hippocampus, were prepared from the ventral (temporal) and the dorsal (septal) parts of the structure. In particular, slices were prepared from the regions extending between about 0.1 and $4.5 \mathrm{~mm}$ from the dorsal and the ventral ends of the hippocampus (Fig. 1a). These slices will be referred to as dorsal (DH) and ventral (VH) hippocampal slices. In each experiment, slices from both $\mathrm{DH}$ and $\mathrm{VH}$ from the same hippocampus or from the hippocampi of the same animal were used. In particular, $227 \mathrm{DH}$ and $233 \mathrm{VH}$ slices were studied. Immediately after sectioning, the slices were transferred to an interface type recording chamber where they were maintained at a constant temperature of $31 \pm 0.5{ }^{\circ} \mathrm{C}$, continuously humidified with a mixed gas containing $95 \% \mathrm{O}_{2}$ and $5 \%$ $\mathrm{CO}_{2}$ and perfused with standard artificial cerebrospinal fluid.

\section{Recordings, data processing and analysis}

Extracellular field recordings from the CA3 or CA1 fields were made using carbon fiber electrodes (diameter 5-10 $\mu \mathrm{m}$, Kation Scientific, or World Precision Instruments Inc., USA). Recordings started at about $1.5 \mathrm{~h}$ after the slices were placed in the recording chamber and they were made either from the CA3 stratum pyramidale or from the CA1 stratum radiatum, as explained in the Results' section. Signals were acquired with a Neurolog amplifier (Digitimer Limited, UK), band-pass filtered at $0.5 \mathrm{~Hz}-2 \mathrm{kHz}$, digitized at $10 \mathrm{kHz}$ and stored in a computer disk using the CED 1401-plus interface and the Signal6 or the Spike2 software (Cambridge Electronic Design, Cambridge, UK) for off-line analysis. Spontaneous field potentials (spfps) and NMDAR-mediated spontaneous field potentials $\left(\mathrm{spfps}_{\text {-nmda }}\right.$ ) were quantified 


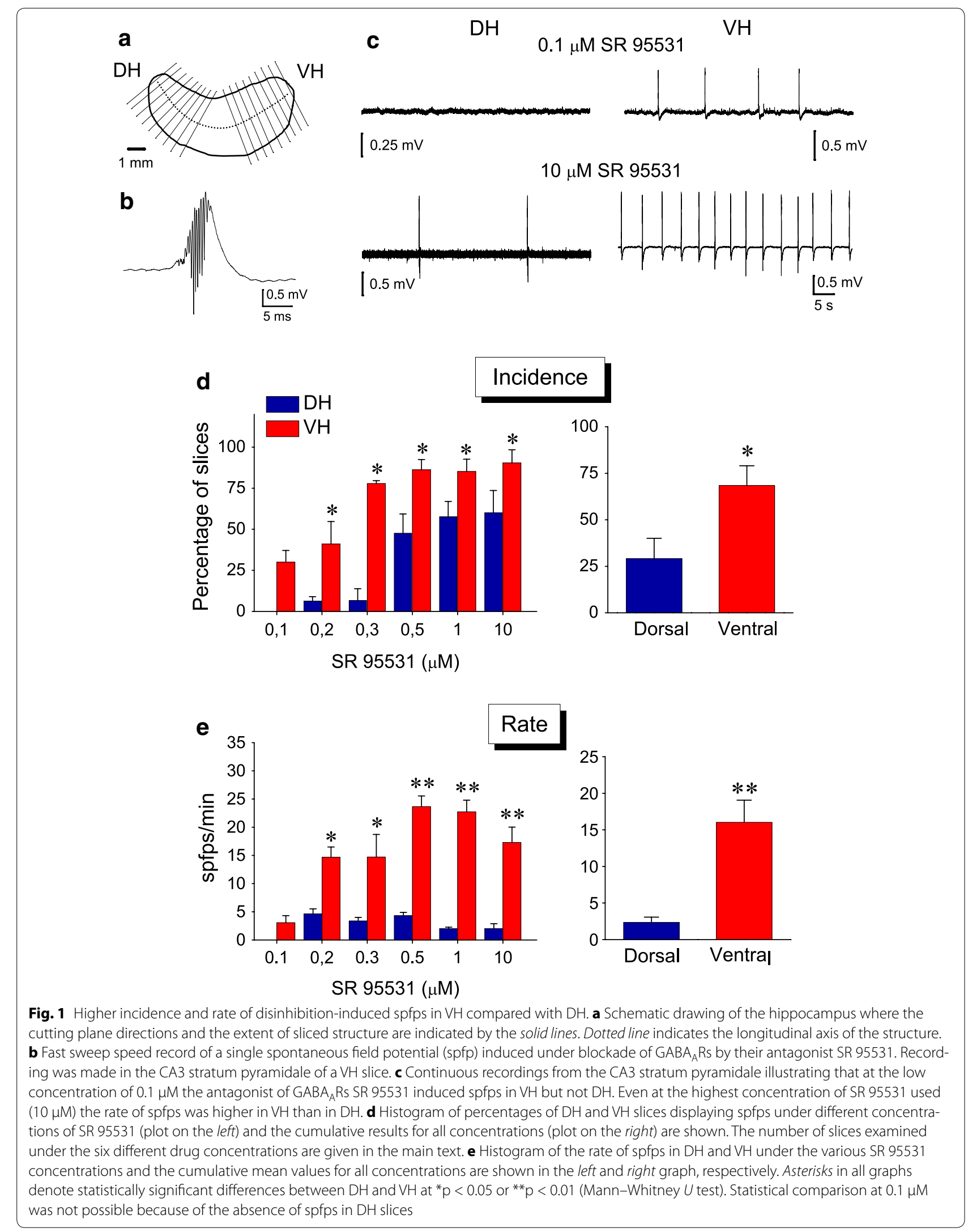


by their incidence, measured as the percentage of slices displaying spontaneous activity in the population of slices studied; the rate of their occurrence, measured as the

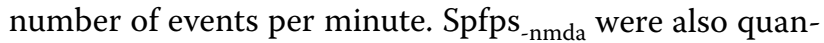
tified by their area, measured as the area circumscribed by the waveform of the negative field potential and the baseline.

\section{Drugs}

The following drugs were used: the antagonist of ionotropic non-NMDARs 6-Cyano-7-nitroquinoxaline-2,3-dione (CNQX), the antagonist of NMDARs 3-((R)-2-carboxypiperazin-4-yl)-propyl-1-phosphonic acid (CPP), the non-competitive antagonist of NMDARs (5S,10R)-(+)-5-methyl-10,11-dihydro-5H-dibenzo[a,d] cyclohepten-5,10-imine maleate (MK 801), the antagonists of $\gamma$-amino-butyric acid type A receptors $\left(\mathrm{GABA}_{\mathrm{A}} \mathrm{R}\right)$ SR 95531, the $\mathrm{GABA}_{\mathrm{A}} \mathrm{R}$ 's channel blocker picrotoxin (PTX), the antagonist of $\mathrm{GABA}_{\mathrm{B}} \mathrm{Rs}$ (3-aminopropyl) (diethoxymethyl) phosphinic acid (CGP 35348), and the agonist of adenosine $A_{1}$ receptors 2-chloroadenosine (adenosine). All drugs were purchased from Tocris Cookson (UK), but PTX and adenosine were obtained from Sigma (USA). They were first dissolved in water, but CNQX was dissolved in dimethyl-sulfoxide (DMSO). The $\mathrm{v} / \mathrm{v}$ concentration of DMSO at the final solution was lower than $0.05 \%$.

\section{Statistics}

The non parametric Wilcoxon and Mann-Whitney $U$ test were used for comparisons inside and between DH and $\mathrm{VH}$ groups of values, respectively. For comparison of percentages the $\chi^{2}$ test was also used. ANOVA was used for comparison between related multiple groups of data. Values throughout the text represent mean \pm SEM; " $n$ " and numbers into parenthesis indicate the number of slices studied.

\section{Results \\ Local network excitation is higher and less effectively controlled by $\mathrm{GABA}_{\mathrm{B}} \mathrm{Rs}$ in $\mathrm{VH}$ compared with $\mathrm{DH}$}

Spontaneous field potentials (spfps) induced under conditions of blockade of $\mathrm{GABA}_{\mathrm{A}}$ Rs (Fig. 1b) were comparatively studied in $\mathrm{DH}$ and $\mathrm{VH}$ slices (Fig. 1c). $\mathrm{GABA}_{\mathrm{A}} \mathrm{R}$-mediated transmission was reduced by applying different concentrations of the antagonist of $\mathrm{GABA}_{\mathrm{A}} \mathrm{R}$ SR 95531, from 0.1 to $10 \mu \mathrm{M}$. The incidence of spfps in the slice population (i.e. the percentage of slices displaying spfps) and the rate of spfps in each drug concentration were measured in $\mathrm{DH}$ and $\mathrm{VH}$. Perfusing slices with increasing concentrations of SR 95531 induced the appearance of spfps in a, respectively, increasing number of slices, in both DH and VH. Furthermore, the incidence of spfps was very different between $\mathrm{DH}$ and $\mathrm{VH}$ at all concentrations of SR 95531 used (Fig. 1d). In particular, the incidence of spfps at the drug concentrations of $0.1,0.2,0.3,0.5,1$ and $10 \mu \mathrm{M}$ were $0 \%(15), 6.3 \pm 2.8 \%$ (32), $11.8 \pm 7.1 \%$ (17), $47.5 \pm 11.8 \%$ (66), $57.6 \pm 9.4 \%$ (57) and $60.0 \pm 13.6 \%$ (35), respectively, in DH and $30.0 \pm 7.1 \%$ (20), $41.0 \pm 13.7 \%$ (31), $77.8 \pm 1.8 \%$ (18), $86.2 \pm 6.2 \%$ (56), $85.2 \pm 7.5$ (37) and $90.4 \pm 8.0 \%$ (32), respectively, in $\mathrm{VH}$. The difference in incidence between $\mathrm{DH}$ and $\mathrm{VH}$ was significantly different at every drug concentration (Mann-Whitney $U$ test and $\chi^{2}$ test, $\mathrm{p}<0.05$ ). The calculation of the total incidence's values (i.e. taking into account all drug concentrations) gave $29.1 \pm 11.0 \%$ for $\mathrm{DH}$ and $68.4 \pm 10.6 \%$ for $\mathrm{VH}$ (Mann-Whitney $U$ test and $\chi^{2}$ test, $\left.\mathrm{p}<0.05\right)$. The rate of spfps was several folds higher in $\mathrm{VH}$ compared with $\mathrm{DH}$ at all drug concentrations (Fig. 1e). In particular, the rate of spfps at the drug concentrations of $0.1,0.2,0.3,0.5,1$ and $10 \mu \mathrm{M}$ were $0,4.7 \pm 0.9 \%$ (2), $3.4 \pm 0.6 \%$ (2), $4.3 \pm 0.6 \%$ (25), $2.0 \pm 0.3 \%$ (30) and $2.0 \pm 0.9 \%(20)$, respectively, in DH and $3.1 \pm 1.3 \%$ (6), $14.7 \pm 1.8 \%(12), 14.8 \pm 4.1 \%$ (13), $23.7 \pm 1.9 \%$ (48), $22.7 \pm 2.1$ (26) and $17.3 \pm 2.7 \%(29)$, respectively, in $\mathrm{VH}$. The difference in the rate of spfps between $\mathrm{DH}$ and $\mathrm{VH}$ was significantly different at every drug concentration (Mann-Whitney $U$-test, $\mathrm{p}<0.05$ or $\mathrm{p}<0.01$, see Fig. 1e). The overall rate of spfps (i.e. taking into account all drug concentrations) was $2.3 \pm 0.7 \mathrm{spfps} /$ min for DH and $16.0 \pm 3.0 \mathrm{spfps} / \mathrm{min}$ for VH (MannWhitney $U$ test, $\mathrm{p}<0.01)$. An interesting observation was that the rate of spfps was significantly correlated with the precise location of the $\mathrm{VH}$ but not $\mathrm{DH}$ slices in the long axis of the structure. As shown in Fig. 2, the rate of spfps was significantly higher in slices taken from more extreme compared with more medial positions in the $\mathrm{VH}$ but not the DH, regardless the concentration of SR 95531. Specifically, the rate of spfps increased from about $5 \mathrm{spfps} / \mathrm{min}$ in slices located $3.5-4.0 \mathrm{~mm}$ from the ventral end to about $35 \mathrm{spfps} / \mathrm{min}$ in the slices obtained from the extreme $1.0 \mathrm{~mm}$ of the VH (ANOVA, $\mathrm{F}=6.29, \mathrm{p}<0.001$ ). On the contrary, the rate of spfps was quite comparable among slices obtained from the DH (ANOVA, $\mathrm{F}=1.85$, $\mathrm{p}>0.1$ ).

In a set of experiments the effects of high concentration of bicuculline $(100 \mu \mathrm{M})$ was examined in slices perfused with SR 95531 and generating spfps. Addition of bicuculline did not significantly change the rate of spfps either in DH or VH slices. Specifically, the rate of spfps under SR 95531 and following addition of bicuculline was $5.4 \pm 1.1$ spfps/min and $5.0 \pm 0.8 \mathrm{spfps} / \mathrm{min}$, respectively, in DH (a change of $1.69 \pm 17.0 \%, \mathrm{n}=7$, Wilcoxon test, $\mathrm{p}>0.05$ ), and $17.5 \pm 2.8 \mathrm{spfps} / \mathrm{min}$ and $20.0 \pm 3.4 \mathrm{spfps} / \mathrm{min}$, respectively, in $\mathrm{VH}$ (a change of $12.6 \pm 8.5 \%, \mathrm{n}=10$, Wilcoxon test, $\mathrm{p}>0.05)$, (Fig. 3a, b). Spfps were abolished 


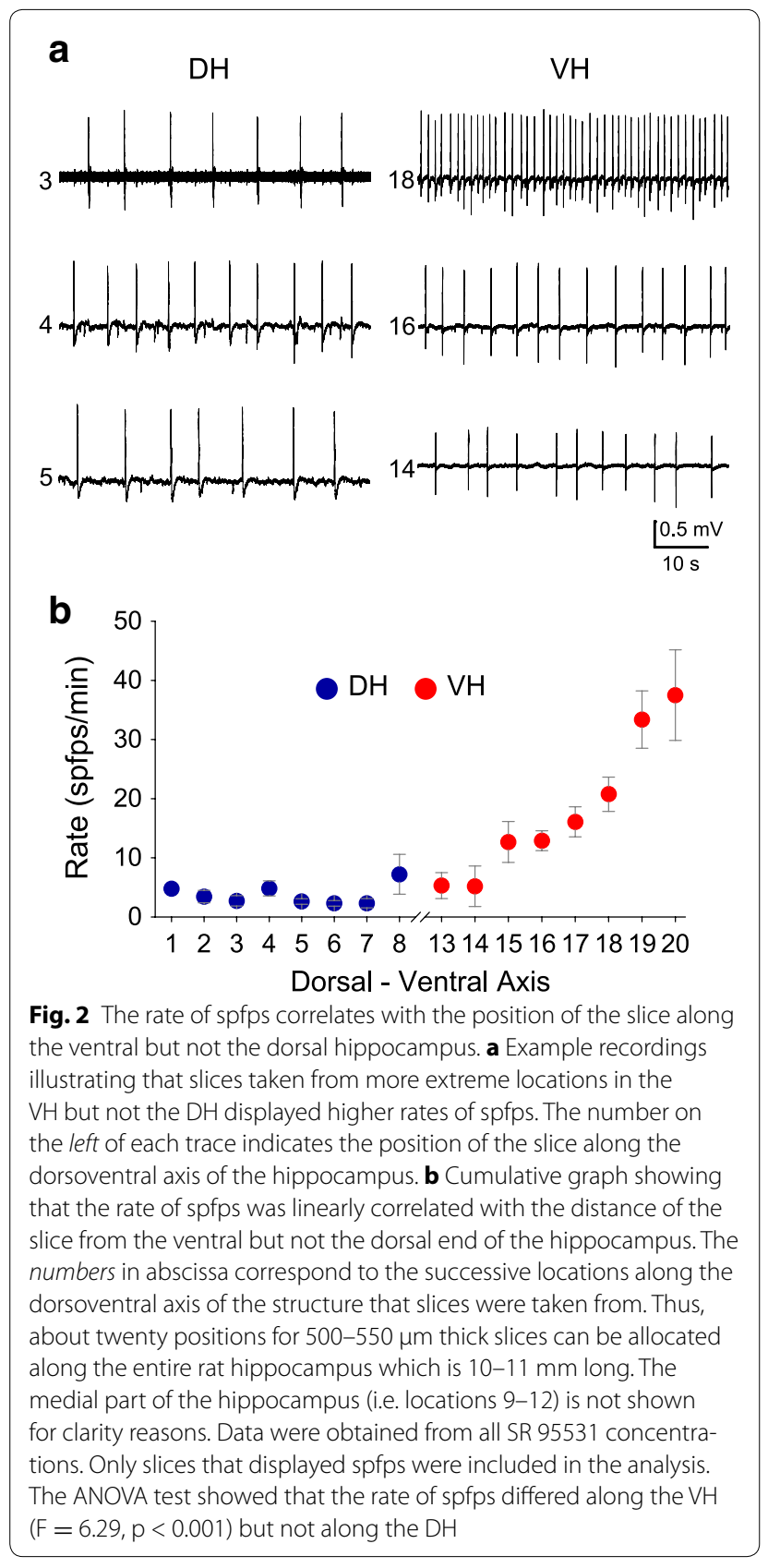

upon addition of $20 \mu \mathrm{M} C \mathrm{CQX}(\mathrm{n}=3$, Fig. 3c) indicating that they required the activity of non-NMDARs.

In addition to $\mathrm{GABA}_{\mathrm{A}} \mathrm{Rs}$, the $\mathrm{GABA}_{\mathrm{B}} \mathrm{R}$-mediated transmission plays an important role in controlling neuronal activity and network excitability [35]. Thus, I examined whether blockade of $\mathrm{GABA}_{B}$ Rs could further enhance excitability in DH and VH by applying CGP $35348(200 \mu \mathrm{M})$ in slices already perfused with $10 \mu \mathrm{M}$ SR 95531. I found that blockade of $G_{A B A} R$ Rs induced a considerable increase in the incidence of spfps in $\mathrm{DH}$ (from $45.9 \pm 10.5$ to $89.6 \pm 4.0 \%, \mathrm{n}=24$, Wilcoxon test and $x^{2}$ test, $\mathrm{p}<0.05$ ) but not in $\mathrm{VH}$ (from 79.4 \pm 12.4 to $95.3 \pm 4.8 \%, \mathrm{n}=9$, Wilcoxon test and $\chi^{2}$ test, $\mathrm{p}>0.05$ ), (Fig. 4). Regarding VH, the blockade of $\mathrm{GABA}_{\mathrm{B}}$ Rs could not have considerable effect since the incidence of spfps in VH slices was already very high under SR 95531. CGP 35348 did not significantly change the rate of spfps either in $\mathrm{DH}$ (from $0.7 \pm 0.1$ to $0.6 \pm 0.1 \mathrm{spfsp} / \mathrm{min}, \mathrm{n}=11$ ) or $\mathrm{VH}$ (from $15.0 \pm 4.3$ to $16.2 \pm 5.7 \mathrm{spfsp} / \mathrm{min}, \mathrm{n}=7$ ), (Fig. 4b). In order to examine whether there is any difference in spfps between $\mathrm{DH}$ and $\mathrm{VH}$ under blockade of only $\mathrm{GABA}_{\mathrm{B}} \mathrm{Rs}$, a population of ten dorsal and eight ventral slices taken from three animals were bathed with CGP 35348 alone. However, the drug did not induce any detectable synchronous field activity in any of the slices studied.

\section{NMDAR-depended network excitation is higher and weakly controlled by $\mathrm{GABA}_{\mathrm{B}} \mathrm{Rs}$ in $\mathrm{VH}$ compared with DH}

NMDARs are a very important component of the excitatory glutamatergic transmission in the hippocampus [36]. Among pyramidal cells those located in the CA1 field display especially large amounts of NMDARs [37]. Recently, it has been shown that NMDARs differ between $\mathrm{DH}$ and $\mathrm{VH}$ in their subunit composition [11], involvement in high-frequency oscillations [38], epileptogenesis $[27,28]$ and participation to short-term synaptic plasticity [39]. In order to examine the relative participation of NMDARs in the network excitability comparatively between $\mathrm{DH}$ and $\mathrm{VH}$, slices were studied under conditions that promote the activity of NMDARs. In particular, slices were bathed with free-magnesium medium

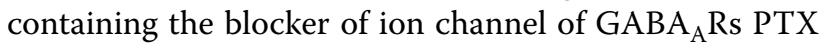
$(50 \mu \mathrm{M})$ and the antagonist of non-NMDARs CNQX $(20 \mu \mathrm{M})$. Taking into account that NMDARs are predominately located in dendrites [40] recordings were made from the CA1 stratum radiatum. Under these conditions spfps were induced in both $\mathrm{DH}$ and $\mathrm{VH}$ slices. These potentials were completely abolished upon perfusion with the antagonist of NMDARs CPP (1-10 $\mu \mathrm{M})$ in both $\mathrm{DH}(\mathrm{n}=13)$ and VH slices $(\mathrm{n}=16)$ or the NMDAR's open channel blocker MK-801 (50 $\mu \mathrm{M}$, in 5 $\mathrm{DH}$ and $5 \mathrm{VH}$ slices), (Fig. 5a, b); therefore they will be called spfps -nmda. $_{\text {Spfps }}$-nmda were also suppressed following activation of adenosine $A_{1}$ receptors by 6-chloroadenosine (5-10 $\mu \mathrm{M})$, (Fig. $5 \mathrm{c}$ ). Given that $\mathrm{A}_{1}$ receptors in CA1 control the neurotransmitter release from glutamatergic terminals [41, 42] these observations showed that the generation of $\operatorname{spfps}_{\text {-nmda }}$ required the activation of postsynaptic NMDARs from glutamate released from presynaptic terminals. Most of the $\mathrm{DH}$ and $\mathrm{VH}$ slices dis-

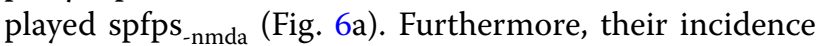




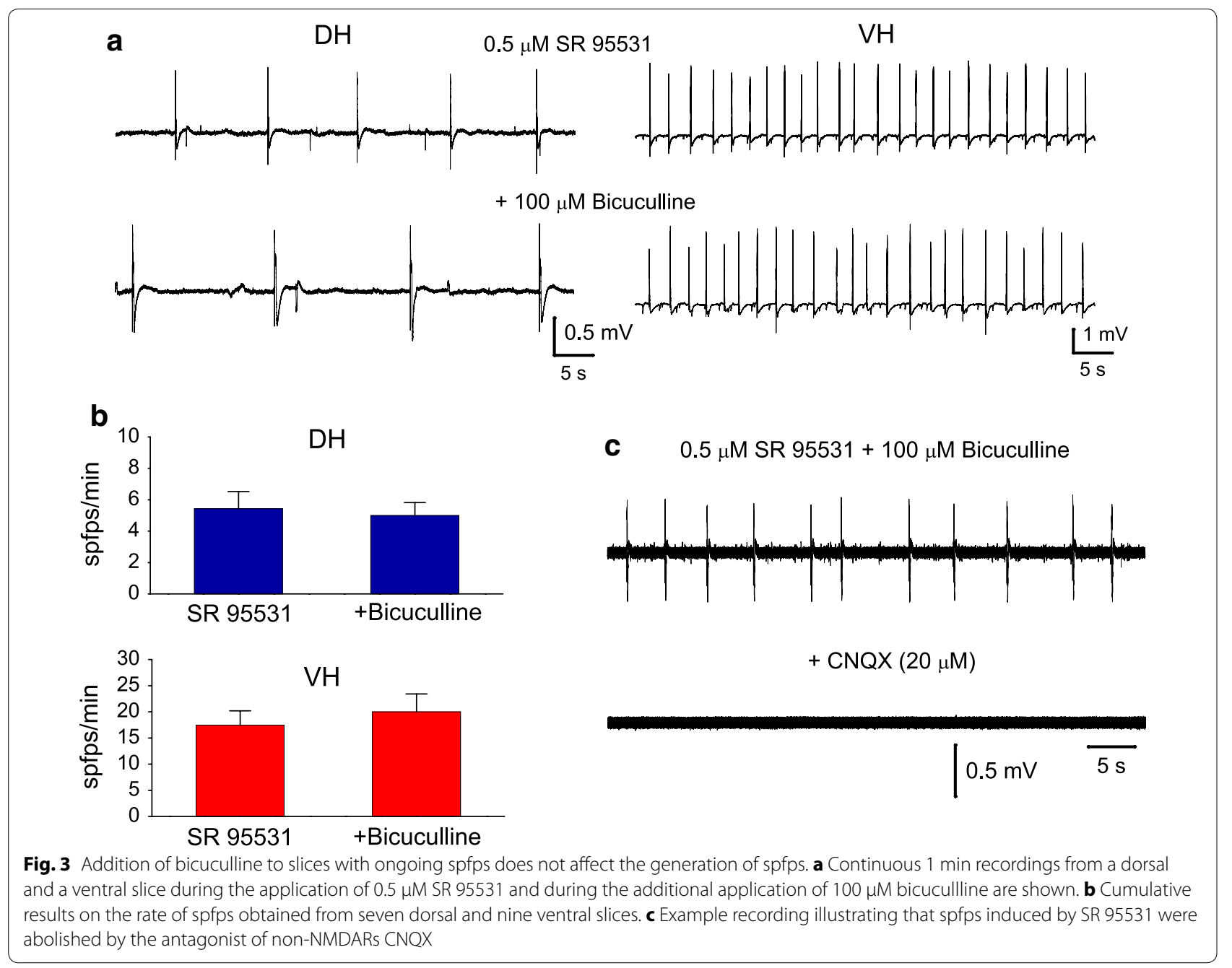

was significantly greater in $\mathrm{VH}(92.3 \pm 4.5 \%$ of slices, 61 slices studied) than in DH (75.4 $\pm 7.5 \%$ of slices, 69 slices studied, comparison between DH and VH; MannWhitney $U$ test and $\chi^{2}$ test, $\mathrm{p}<0.05$ ), (Fig. 6b). In addition, and in similarity with spfps, spfps $_{\text {-nmda }}$ occurred at a much faster rate in $\mathrm{VH}(13.2 \pm 1.5$ events/min, $\mathrm{n}=55)$ compared with $\mathrm{DH}(3.7 \pm 0.4$ events $/ \mathrm{min}, \mathrm{n}=54)$, (Mann-Whitney $U$ test, $\mathrm{p}<0.001$, Fig. 6c). Furthermore, spfp- ${ }_{\text {nmda }}$ were significantly greater in $\mathrm{VH}$ than in $\mathrm{DH}$. Specifically, the area of single spfps $_{\text {-nmda }}$ was two-fold higher in $\mathrm{VH}(180.8 \pm 25.0 \mathrm{mV} \times \mathrm{ms}, \mathrm{n}=44)$ compared with $\mathrm{DH}$ slices $(91.8 \pm 14.3 \mathrm{mV} \times \mathrm{ms}, \mathrm{n}=32)$, (MannWhitney $U$ test, $\mathrm{p}<0.001)$. This is consistent with the higher extracellular concentration of glutamate in $\mathrm{VH}$ compared with $\mathrm{DH}[8,43]$, given that ambient glutamate activates NMDARs in CA1 pyramidal cells [44].

In similarity with spfps, the rate of $\operatorname{spfps}_{- \text {nmda }}$ was a function of the precise position of slice in $\mathrm{VH}$ but not $\mathrm{DH}$ (Fig. 6c). Specifically, VH slices taken from progressively more extreme positions, toward the ventral end of the structure, displayed higher rates of spfps-nmda than slices obtained from more medial positions (ANOVA, $\mathrm{F}=2.5$, $\mathrm{p}<0.05$ ), (Fig. 6b). Such a correlation was not observed in DH slices (ANOVA, F $=0.87$, $\mathrm{p}>0.5$ ).

$\mathrm{GABA}_{\mathrm{B}} \mathrm{R}$-mediated transmission exerts a powerful control on NMDARs $[45,46]$. Thus I examined the involvement of $\mathrm{GABA}_{\mathrm{B}}$ receptors in the generation of spfp- ${ }_{\text {nmda }}$. The $\mathrm{GABA}_{\mathrm{B}} \mathrm{R}$ antagonist CGP 35348 was applied to DH and VH slices perfused with PTX and CNQX (Fig. 7a). Blockade of $\mathrm{GABA}_{\mathrm{B}} \mathrm{Rs}$ increased the incidence of spfpnmda in the population of both $\mathrm{DH}$ and $\mathrm{VH}$ slices. In particular, of the previously silent slices sixteen out of seventeen dorsal $(94.5 \pm 5.6 \%)$ and all five ventral slices $(100 \pm 0 \%)$ exhibited spfp- ${ }_{\text {nmda }}$ following addition of CGP 35348. The difference in the percentage of slices displaying spfps $_{-n m d a}$ before (i.e. under PTX + CNQX) and following addition of CGP 35348 was significantly higher in $\mathrm{DH}(35.8 \pm 10.4 \%)$ than in $\mathrm{VH}(8.5 \pm 5.6 \%$; 


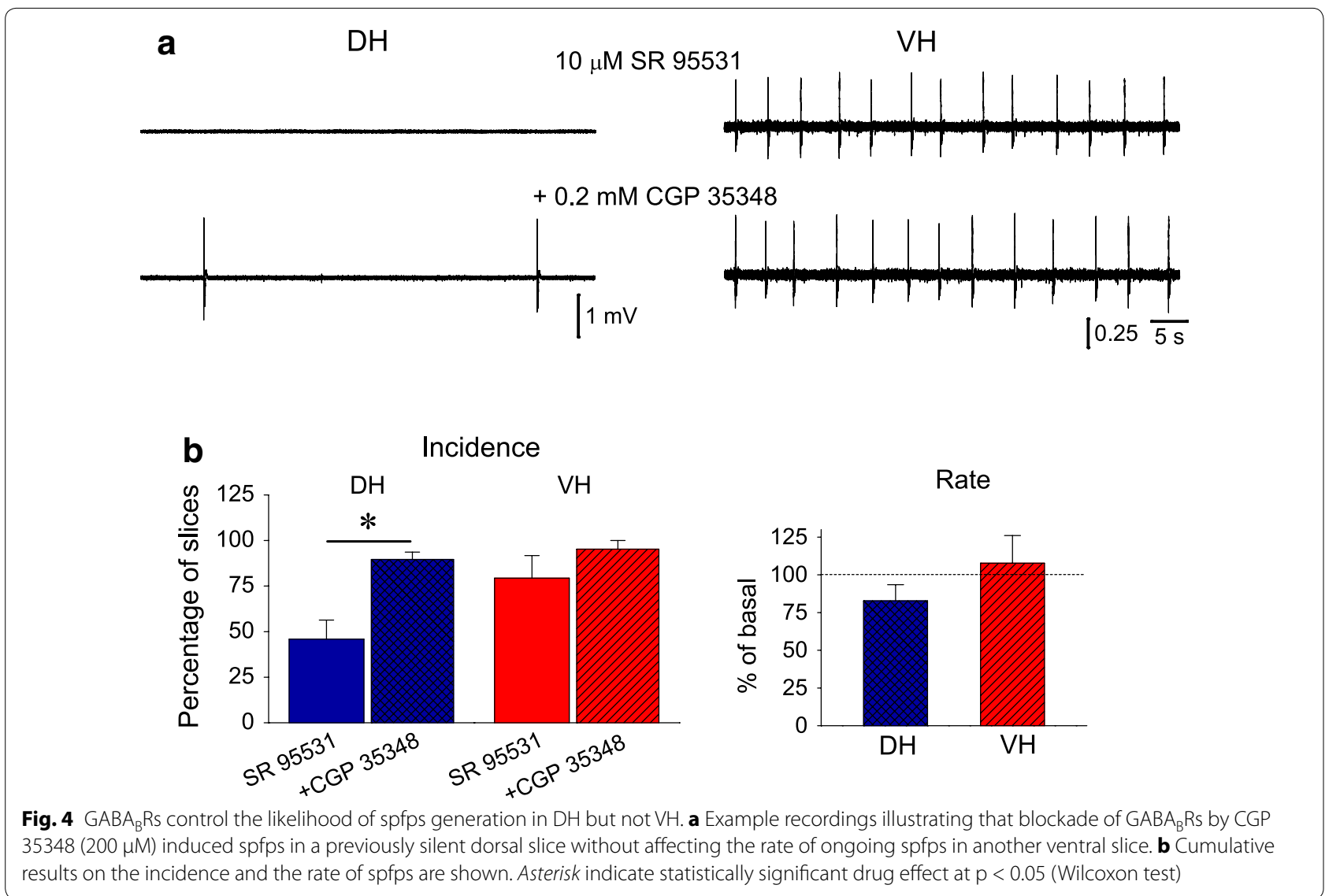

Mann-Whitney $U$ test and $\chi^{2}$ test, $\mathrm{p}<0.05$; Fig. 7b). As a consequence, the incidence of spfps ${ }_{\text {-nmda }}$ observed under all three drugs (i.e. PTX + CNQX + CGP 35348) became similar between DH (68 out of 69 slices, $98.6 \%$ ) and VH (61 out of 61 slices, $100 \%$ ). Blockade of $\mathrm{GABA}_{B}$ Rs significantly increased in the rate of spfp- ${ }_{\text {nmda }}$ similarly in DH (by $32.7 \pm 3.7 \%$, from $4.2 \pm 0.5$ to $6.1 \pm 0.6$ events/ min, $\mathrm{n}=38, \mathrm{p}<0.001$ ) and $\mathrm{VH}$ (by $38.2 \pm 3.5 \%$, from $13.3 \pm 1.8$ to $17.6 \pm 1.8$ events $/ \mathrm{min}, \mathrm{n}=39, \mathrm{p}<0.001)$, (Fig. 7b). Importantly, CGP 35348 produced a significant increase in the area of single spfp- ${ }_{\text {nmda }}$ in DH (by $49.5 \pm 11 \%$, from $70.8 \pm 14.5$ to $102.2 \pm 22.8 \mathrm{mV} \times$ ms, $\mathrm{n}=20$, Wilcoxon test, $\mathrm{p}<0.05$ ) but not $\mathrm{VH}$ (by $16.1 \pm 5.3 \%$, from $186.8 \pm 28.1$ to $192.3 \pm 24.2 \mathrm{mV} \times$ $\mathrm{ms}, \mathrm{n}=33, \mathrm{p}>0.05$ ), (Fig. 7b). However, the area of single spfp- nmda remained significantly greater in $\mathrm{VH}$ compared with DH slices $(192.3 \pm 24.2$ vs $102.2 \pm 22.8 \mathrm{mV} \times$ ms, Mann-Whitney $U$ test, $\mathrm{p}<0.01$ ).

\section{Discussion}

This study shows that under blockade of GABAergic transmission the local neuronal circuitry of the hippocampus is more excitable in the ventral than its dorsal segment with the considerable participation of
NMDARs. Furthermore, the relatively weaker control of excitation by $\mathrm{GABA}_{\mathrm{B}} \mathrm{Rs}$ appears to play an important role in the higher proneness of the ventral hippocampus to spontaneous activation.

One well proven difference between the $\mathrm{DH}$ and $\mathrm{VH}$ neuronal network is the propensity of the later to epileptic activity $[4,7,19-30]$. A characteristic expression of the particular excitability of $\mathrm{VH}$ compared with the $\mathrm{DH}$ is the higher rate of occurrence of recurrent synchronous discharges, observed especially in the in vitro hippocampal preparations under conditions of increased potassium or decreased magnesium concentration in the extracellular medium [4, 22, 26-28]. In keeping with these observations and using for the first time the experimental model of gradually increased disinhibition it is shown that the VH compared with DH displays higher rates of spfps and

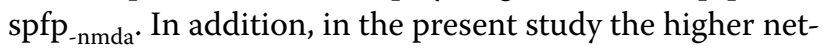
work excitability of $\mathrm{VH}$ was also expressed by the greater incidence of spfps and spfps $_{\text {-nmda }}$ and the larger area of spfps $_{\text {-nmda }}$ under intact $\mathrm{GABA}_{B} \mathrm{R}$-mediated inhibition. In particular, the present results show that the intrinsic circuitry of $\mathrm{VH}$ is more prone to spontaneous activation at any level of gradual reduction of $\mathrm{GABA}_{\mathrm{A}} \mathrm{R}$-mediated transmission. 


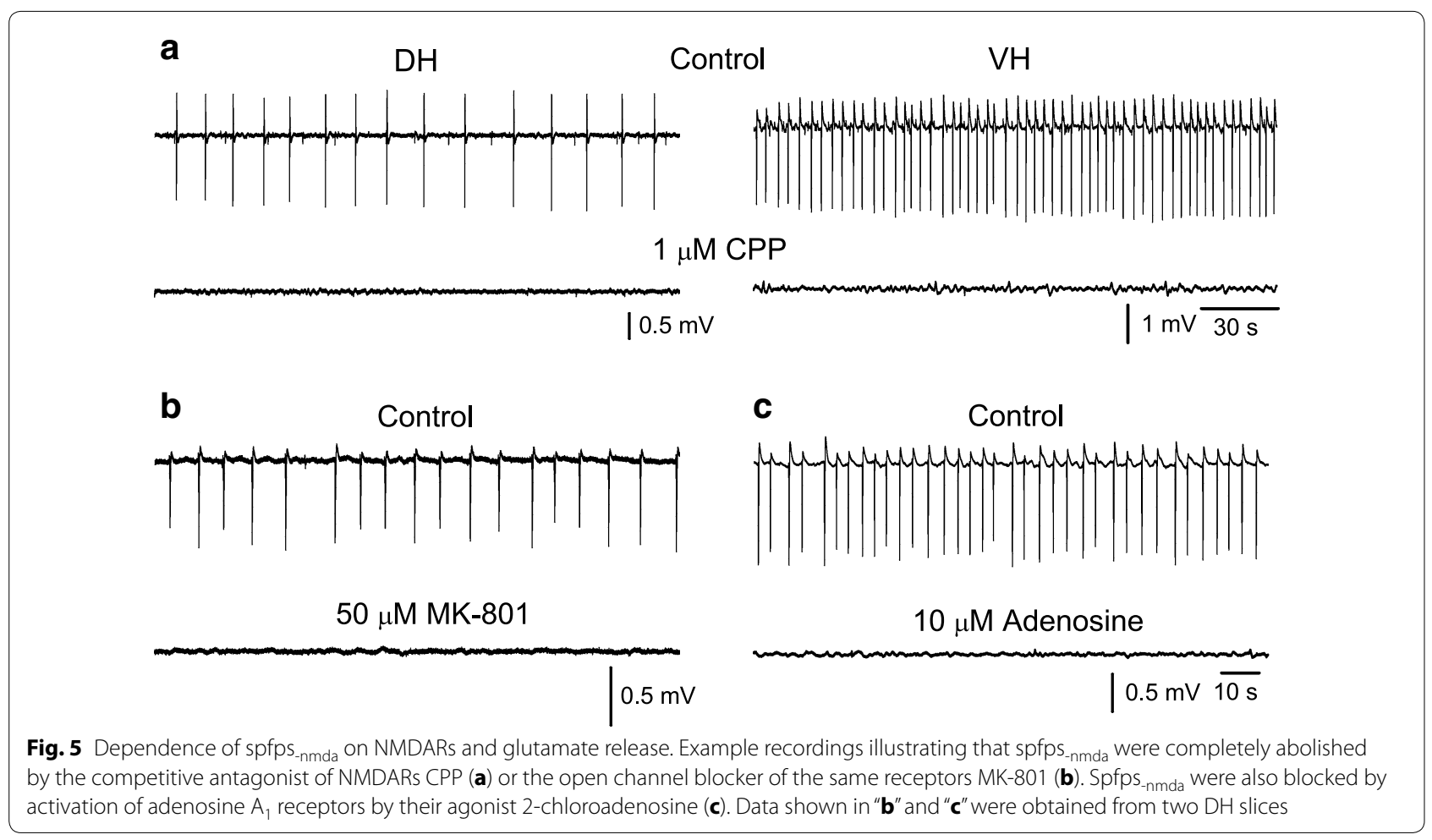

Several mechanisms have been proposed to contribute to the higher intrinsic excitability in the $\mathrm{VH}$, including the excitatory and the inhibitory synaptic actions. For instance, in the CA1 field of the $\mathrm{VH}$ vs $\mathrm{DH}$ the $\mathrm{GABA}_{\mathrm{A}} \mathrm{R}$-mediated transmission is lower as evidenced by the impact of inhibitory recurrent circuit on the firing of principal cells $[12,13]$ and the different composition of $\mathrm{GABA}_{\mathrm{A}} \mathrm{Rs}$ [14]. Furthermore, the different subunit composition of NMDARs [11] and their different participation in the epileptogenesis between the two hippocampal poles $[27,28]$ has suggested that NMDARs are functionally distinct between DH and VH. Cholinergic transmission may also play a significant role in the network excitability [26]. Apparently, a plethora of molecular, synaptic, cellular and circuit mechanisms contribute to the different excitability of the local neuronal circuitry between DH and VH. One of the major factors contributing to increased network excitability is the relatively low effectiveness of the synaptic inhibition [47]. The disinhibition model used in the present study presents some advantages, including the fact that neuronal excitation that lead to synchronized field potentials can be studied in isolation from the confounding mechanisms of synaptic inhibition [33]. Hence, the higher rates of spontaneous network activation observed here under blockade of GABAergic inhibition suggest that the relative contribution of the neuronal excitation in the local neuronal circuitry is higher in the $\mathrm{VH}$ compared with the $\mathrm{DH}$. Indeed, recent observations have shown that the pyramidal neurons of the ventral hippocampus are more excitable compared with their dorsal counterparts $[48,49]$.

$\mathrm{GABA}_{\mathrm{B}} \mathrm{Rs}$ modulate network excitation [35] and especially NMDAR-depended activity $[45,46]$. The fact that blockade of $\mathrm{GABA}_{\mathrm{B}} \mathrm{Rs}$ increased the proportion of slices that displayed either spfps or spfps $_{\text {-nmda }}$, suggests that $\mathrm{GABA}_{\mathrm{B}} \mathrm{R}$-mediated transmission regulates the excitation threshold in the local circuitry as for example occurs in the subiculum [34] and control synchronous discharges [50]. Importantly, the present results show that $\mathrm{GABA}_{B} \mathrm{Rs}$ effectively control the overall network excitability in $\mathrm{DH}$ but not $\mathrm{VH}$. What is more, thought GABA $_{B}$ Rs restricted NMDAR-depended network excitation in both $\mathrm{DH}$ and $\mathrm{VH}$, this effect was considerably stronger in $\mathrm{DH}$. This is the first time that $\mathrm{GABA}_{\mathrm{B}} \mathrm{Rs}$ are shown to be differently involved in regulating and controlling total and NMDAR-depended network excitability between $\mathrm{DH}$ and $\mathrm{VH}$.

The intrinsic excitability of a local neuronal network is the expression of the balance between excitation and inhibition that dynamically tunes the function and therefore the output of a local neuronal circuit into a specific mode at any given instance. It is proposed that NMDARs and $\mathrm{GABA}_{B}$ Rs play significant 

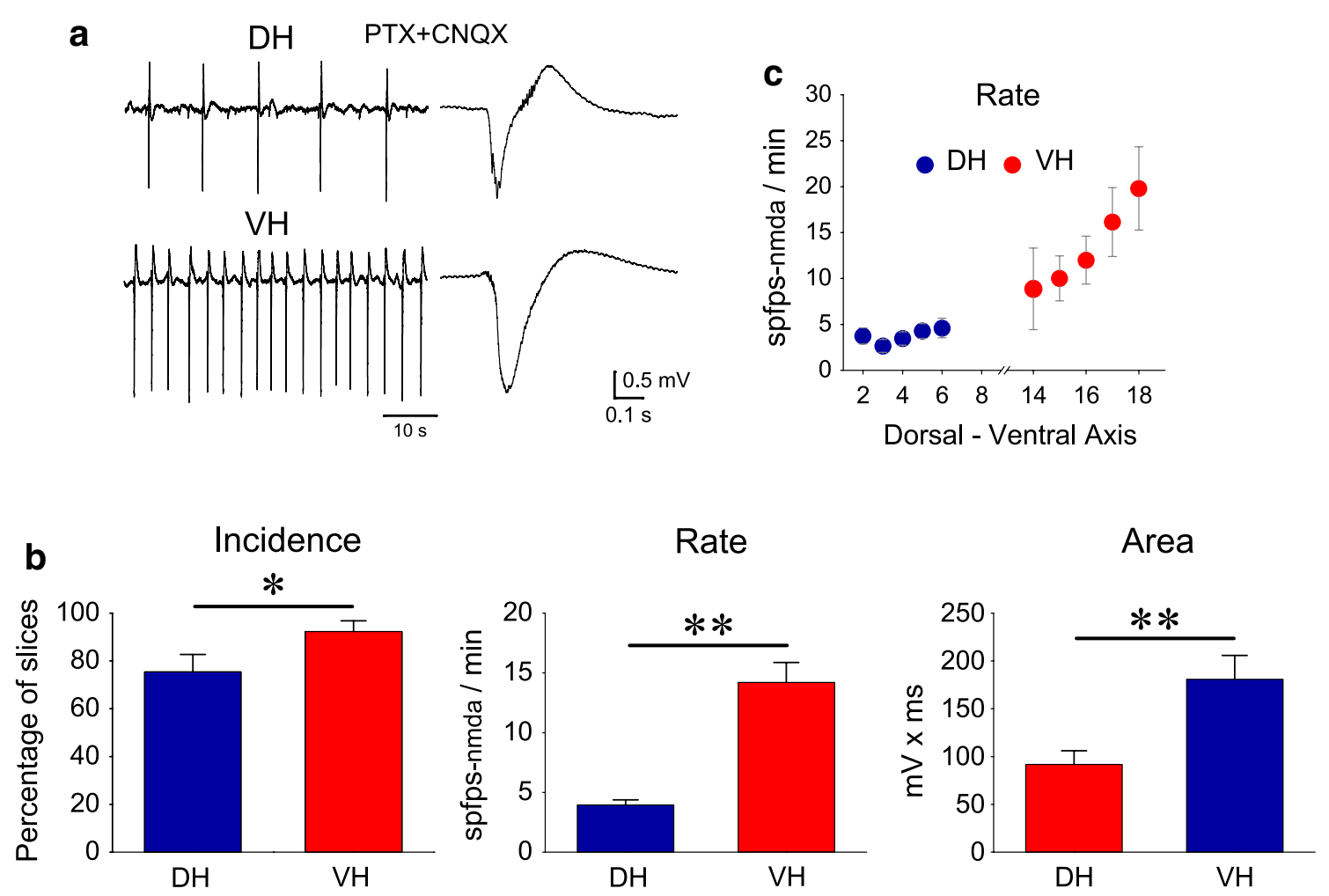

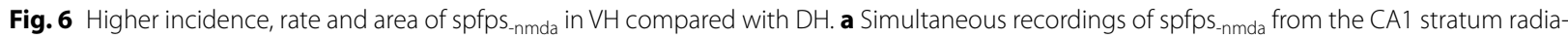
tum of a DH and a VH slice taken from the same animal and bathed in $50 \mu \mathrm{M} \mathrm{PTX}$ and $20 \mu \mathrm{M}$ CNQX. One minute-long records (traces on the left) and single events (traces on the right) are shown. Note that spfps-nmda was larger and occurred at a higher rate in VH compared with the DH slice. $\mathbf{b}$ The incidence, rate and area of spfps_nmda were significantly greater in VH compared with DH slices. Asterisks denote statistical significance between $\mathrm{DH}$ and $\mathrm{VH}$ values (Mann-Whitney $U$ test test, at ${ }^{*} \mathrm{p}<0.05$ or ${ }^{* *} \mathrm{p}<0.005$ ). c Diagram illustrating the relationship between the rate of occurrence

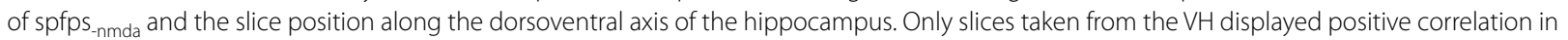
their rates of spfps $_{-n m d a}$ as approached the end of the hippocampus structure $(F=2.5, p<0.05)$. Note that slices taken from the most extreme positions did not show spfps $_{\text {-nmda. }}$. The medial part of the hippocampus (i.e. locations 9-13) is not shown for clarity

roles in sculpting this balance in $\mathrm{DH}$ and $\mathrm{VH}$. It has been shown that partial blockade of inhibition leads to network oscillations [33]. It is noted that spontaneous activation of the $\mathrm{VH}$ local network occurred even at small reductions in $\mathrm{GABA}_{\mathrm{A}}$ Rergic inhibition induced by small concentrations of SR 95531. Small reductions of GABAergic inhibition such as those used in the present study favor the activity of sharp wave-ripples [51] which is the only one physiological endogenous network activity of the hippocampus. Actually, the generation of the ripple oscillation requires an accurate balance between excitation and inhibition in the local circuitry [52]. The higher excitability of the $\mathrm{VH}$ implies that physiological activation of the hippocampal network may arise from this part of the hippocampus. This should have important implications for the processing of the incoming information in the hippocampal circuitry. Indeed, the activity of sharp waves is self-organized with greater probability in ventral compared with dorsal hippocampal slices
[53]. Similarly, sharp waves first emerge in the ventral segment of the hippocampus and then spread toward its dorsal end or they remain localized in the ventral pole [54]. It is then postulated that the higher network excitability of $\mathrm{VH}$ is the manifestation of the particular functional demands assigned to this part of the hippocampus.

\section{Conclusion}

The present results show that $\mathrm{GABA}_{B}$ Rs and NMDARs importantly contribute to the higher intrinsic excitability of the $\mathrm{VH}$ compared with the DH local circuitry. The higher excitability of the VH intrinsic network may express the different way of information processing performed from the ventral compared with the dorsal segment of the hippocampus. It is hypothesized that functional specializations of basic local network parameters such as $G_{A B A} R$ s and NMDARs support the distinct roles played by $\mathrm{DH}$ and $\mathrm{VH}$ networks. Adaptive modifications in other parameters of the neural 

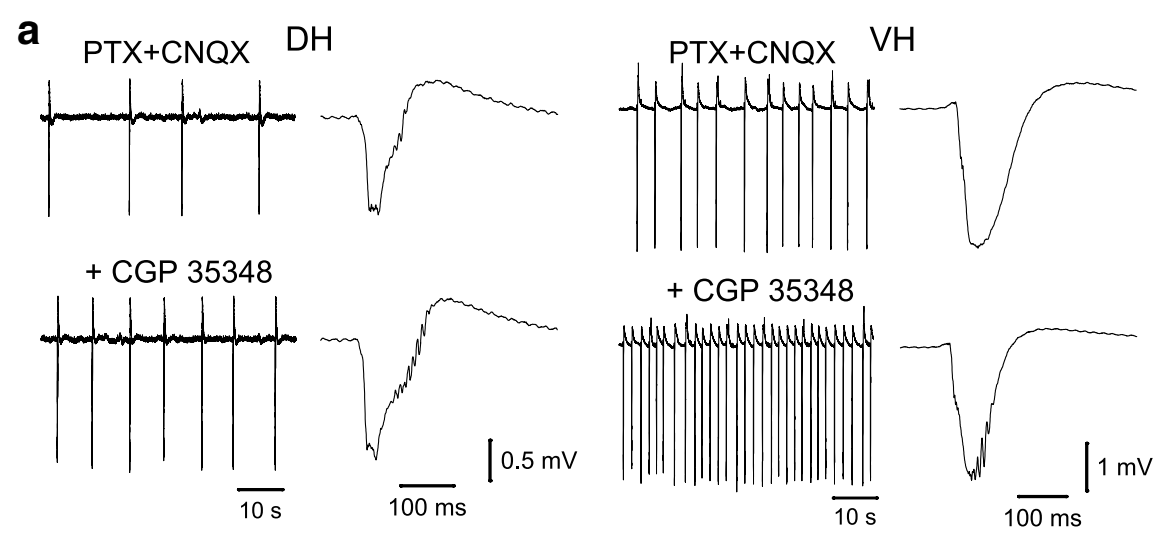

b
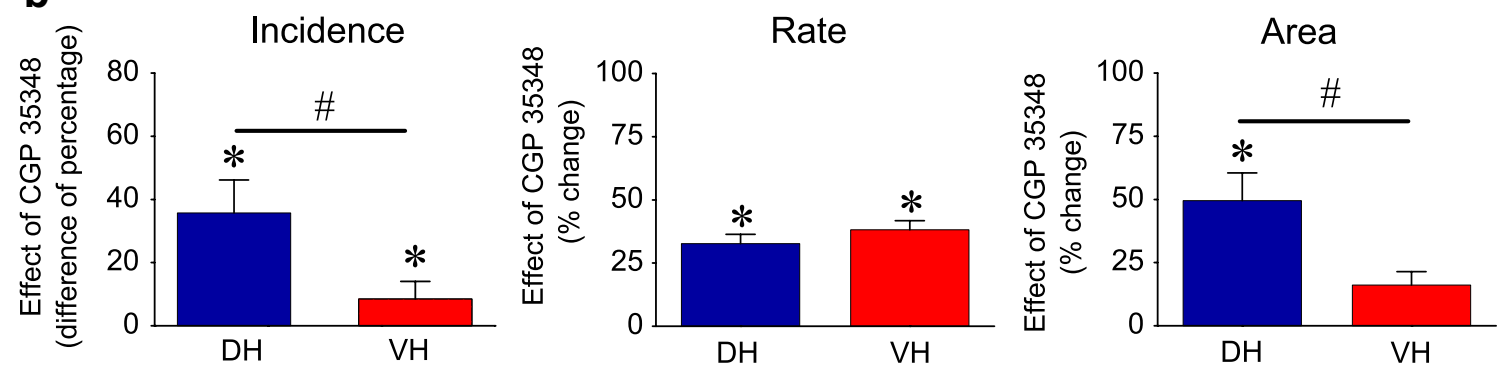

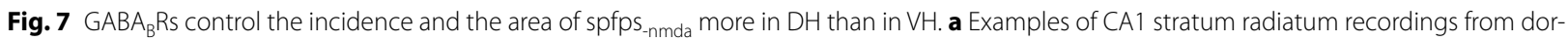

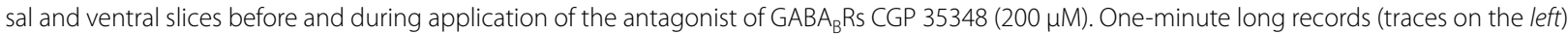
and single events (traces on the right) from each slice are shown. Note that although the rate of spfps_nmda was similarly accelerated by CGP 35348 in the dorsal and ventral slices, single events became larger only in the dorsal slice. $\mathbf{b}$ Cumulative data showing that blockade of $\mathrm{GABA}_{B} R_{\mathrm{Ss}}$ increased the incidence and area of spfps -nmda $_{\text {more in }} \mathrm{DH}$ than in VH. The effect of CGP 35348 on the incidence is given as the difference in the percentage of slices displaying spfps_nmda before and after application of CGP 35348. Asterisks indicate statistically significant drug effects at $p<0.05$ in each group (Wilcoxon test). Diesis indicates significant differences in the drug effect between DH and VH (Mann-Whitney $U$ test, $p<0.05$ )

circuitry contribute to keeping excitation/inhibition balance into the homeostatically regulated physiological range.

\section{Acknowledgements}

This research has been co-financed by the European Union (European Social Fund-ESF) and Greek national funds through the Operational Program 'Education-and-Lifelong-Learning' of the National Strategic Reference Framework (NSRF)-Research Funding Program: Thales. Investing in knowledge society through the European Social Fund; (\# MIS: 380342).

\section{Competing interests}

The author declare that they have no competing interests.

Received: 3 August 2015 Accepted: 4 November 2015

Published online: 10 November 2015

\section{References}

1. Liu G. Local structural balance and functional interaction of excitatory and inhibitory synapses in hippocampal dendrites. Nat Neurosci. 2004;7(4):373-9.

2. Buzsaki G. Rhythms of the brain. Oxford: Oxford University Press; 2006

3. Andersen P, Bliss TV, Skrede KK. Lamellar organization of hippocampal pathways. Exp Brain Res. 1971;13(2):222-38.
4. Bragdon AC, Taylor DM, Wilson WA. Potassium-induced epileptiform activity in area CA3 varies markedly along the septotemporal axis of the rat hippocampus. Brain Res. 1986;378(1):169-73.

5. Gage FH, Thompson RG. Differential distribution of norepinephrine and serotonin along the dorsal-ventral axis of the hippocampal formation. Brain Res Bull. 1980;5(6):771-3.

6. Gall C, Brecha N, Karten HJ, Chang KJ. Localization of enkephalin-like immunoreactivity to identified axonal and neuronal populations of the rat hippocampus. J Comp Neurol. 1981;198(2):335-50.

7. Gillbert M, Racine RJ, Smith GK. Epileptiform burst responses in ventral vs dorsal hippocampal slices. Brain Res. 1985;361(1-2):389-91.

8. Hortnagl H, Berger ML, Sperk G, Pifl C. Regional heterogeneity in the distribution of neurotransmitter markers in the rat hippocampus. Neuroscience. 1991:45(2):261-72.

9. Lee KS, Schubert P, Reddington M, Kreutzberg GW. Adenosine receptor density and the depression of evoked neuronal activity in the rat hippocampus in vitro. Neurosci Lett. 1983;37(1):81-5.

10. Verney C, Baulac M, Berger B, Alvarez C, Vigny A, Helle KB. Morphological evidence for a dopaminergic terminal field in the hippocampal formation of young and adult rat. Neuroscience. 1985;14(4):1039-52.

11. Pandis C, Sotiriou E, Kouvaras E, Asprodini E, Papatheodoropoulos C, Angelatou F. Differential expression of NMDA and AMPA receptor subunits in rat dorsal and ventral hippocampus. Neuroscience. 2006;140(1):163-75.

12. Papatheodoropoulos C, Asprodini E, Nikita I, Koutsona C, Kostopoulos G. Weaker synaptic inhibition in CA1 region of ventral compared to dorsal rat hippocampal slices. Brain Res. 2002;948(1-2):117-21. 
13. Petrides T, Georgopoulos P, Kostopoulos G, Papatheodoropoulos C. The GABAA receptor-mediated recurrent inhibition in ventral compared with dorsal CA1 hippocampal region is weaker, decays faster and lasts less. Exp Brain Res. 2007;177(3):370-83.

14. Sotiriou E, Papatheodoropoulos C, Angelatou F. Differential expression of gamma-aminobutyric acid-a receptor subunits in rat dorsal and ventral hippocampus. J Neurosci Res. 2005;82(5):690-700.

15. Colgin LL, Kubota D, Jia Y, Rex CS, Lynch G. Long-term potentiation is impaired in rat hippocampal slices that produce spontaneous sharp waves. J Physiol. 2004;558(Pt 3):953-61.

16. Maggio N, Segal M. Differential modulation of long-term depression by acute stress in the rat dorsal and ventral hippocampus. J Neurosci. 2009;29(27):8633-8.

17. Maruki K, Izaki Y, Nomura M, Yamauchi T. Differences in paired-pulse facilitation and long-term potentiation between dorsal and ventral CA1 regions in anesthetized rats. Hippocampus. 2001;11(6):655-61.

18. Papatheodoropoulos C, Kostopoulos G. Decreased ability of rat temporal hippocampal CA1 region to produce long-term potentiation. Neurosci Lett. 2000;279(3):177-80.

19. Andy OJ. Electrophysiological comparisons of the dorsal and ventral hippocampus. In: Physiologie de I'Hippocampe. Paris: CNRS; 1962. pp. 411-27.

20. Brazier MA. Regional activities within the human hippocampus and hippocampal gyrus. Exp Neurol. 1970;26(2):254-68.

21. Becker A, Letzel K, Letzel U, Grecksch G. Kindling of the dorsal and the ventral hippocampus: effects on learning performance in rats. Physiol Behav. 1997;62(6):1265-71.

22. Derchansky M, Shahar E, Wennberg RA, Samoilova M, Jahromi SS, Abdelmalik PA, Zhang L, Carlen PL. Model of frequent, recurrent, and spontaneous seizures in the intact mouse hippocampus. Hippocampus. 2004;14(8):935-47.

23. Greco B, Prevost J, Gioanni Y. Intracerebral microinjections of dermorphin: search for the epileptic induction thresholds. NeuroReport. 1994;5(16):2169-72.

24. Lerner-Natoli M, Rondouin G, Baldy-Moulinier M. Hippocampal kindling in the rat: intrastructural differences. J Neurosci Res. 1984;12(1):101-11.

25. Lothman EW, Collins RC. Kainic acid induced limbic seizures: metabolic, behavioral, electroencephalographic and neuropathological correlates. Brain Res. 1981;218(1-2):299-318.

26. Mikroulis AV, Psarropoulou C. Endogenous ACh effects on NMDAinduced interictal-like discharges along the septotemporal hippocampal axis of adult rats and their modulation by an early life generalized seizure. Epilepsia. 2012;53(5):879-87.

27. Moschovos C, Kostopoulos G, Papatheodoropoulos C. Endogenous adenosine induces NMDA receptor-independent persistent epileptiform discharges in dorsal and ventral hippocampus via activation of A2 receptors. Epilepsy Res. 2012;100(1-2):157-67.

28. Papatheodoropoulos C, Moschovos C, Kostopoulos G. Greater contribution of $\mathrm{N}$-methyl-D-aspartic acid receptors in ventral compared to dorsal hippocampal slices in the expression and long-term maintenance of epileptiform activity. Neuroscience. 2005;135(3):765-79.

29. Racine R, Rose PA, Burnham WM. Afterdischarge thresholds and kindling rates in dorsal and ventral hippocampus and dentate gyrus. Can J Neurol Sci. 1977;4(4):273-8.

30. Lee PH, Xie CW, Lewis DV, Wilson WA, Mitchell CL, Hong JS. Opioidinduced epileptiform bursting in hippocampal slices: higher susceptibility in ventral than dorsal hippocampus. J Pharmacol Exp Ther. 1990;253(2):545-51.

31. Andersen P. Inhibitory circuits in the thalamus and hippocampus-an appraisal after 40 years. Prog Neurobiol. 2006;78(3-5):264-71.

32. Traub RD, Miles R. Collective behaviors of the CA3 network. In: Traub RD, Miles R, editors. Neuronal networks of the hippocampus. Oxford University Press; 1991. pp. 119-56.

33. Traub RD, Jefferys JG, Whittington JR. Networks of pyramidal cells: synchronized bursts. In: Traub RD, Jefferys JG, Whittington JR, editors. Fast oscillations in cortical circuits. Oxford University Press; 2000. pp. 73-102.

34. Stanford IM, Traub RD, Jefferys JG. Limbic gamma rhythms. II. Synaptic and intrinsic mechanisms underlying spike doublets in oscillating subicular neurons. J Neurophysiol. 1998;80(1):162-71.
35. Craig MT, McBain CJ. The emerging role of $G A B A B$ receptors as regulators of network dynamics: fast actions from a 'slow' receptor? Curr Opin Neurobiol. 2014;26:15-21.

36. Hestrin S, Nicoll RA, Perkel DJ, Sah P. Analysis of excitatory synaptic action in pyramidal cells using whole-cell recording from rat hippocampal slices. J Physiol. 1990;422:203-25.

37. Monaghan DT, Cotman CW. Distribution of N-methyl-D-aspartatesensitive L-[3H]glutamate-binding sites in rat brain. J Neurosci. 1985;5(11):2909-19.

38. Papatheodoropoulos C. NMDA receptor-dependent high-frequency network oscillations $(100-300 \mathrm{~Hz})$ in rat hippocampal slices. Neurosci Lett. 2007;414(3):197-202.

39. Papatheodoropoulos C. Striking differences in synaptic facilitation along the dorsoventral axis of the hippocampus. Neuroscience. 2015;301:454-70

40. Monaghan DT, Yao D, Olverman HJ, Watkins JC, Cotman CW. Autoradiography of D-2-[3H]amino-5-phosphonopentanoate binding sites in rat brain. Neurosci Lett. 1984;52(3):253-8.

41. Asztely F, Xiao MY, Wigstrom H, Gustafsson B. Effect of adenosine-induced changes in presynaptic release probability on long-term potentiation in the hippocampal CA1 region. J Neurosci. 1994;14(11 Pt 1):6707-14.

42. Yoon KW, Rothman SM. Adenosine inhibits excitatory but not inhibitory synaptic transmission in the hippocampus. J Neurosci. 1991;11(5):1375-80.

43. Jeltsch H, Bertrand F, Lazarus C, Cassel JC. Cognitive performances and locomotor activity following dentate granule cell damage in rats: role of lesion extent and type of memory tested. Neurobiol Learn Mem. 2001;76(1):81-105.

44. Sah P, Hestrin S, Nicoll RA. Tonic activation of NMDA receptors by ambient glutamate enhances excitability of neurons. Science. 1989;246(4931):815-8.

45. Brown JT, Gill CH, Farmer CE, Lanneau C, Randall AD, Pangalos MN, Collingridge GL, Davies $\mathrm{CH}$. Mechanisms contributing to the exacerbated epileptiform activity in hippocampal slices of GABAB1 receptor subunit knockout mice. Epilepsy Res. 2003;57(2-3):121-36.

46. Morrisett RA, Mott DD, Lewis DV, Swartzwelder HS, Wilson WA. GABABreceptor-mediated inhibition of the $\mathrm{N}$-methyl-D-aspartate component of synaptic transmission in the rat hippocampus. J Neurosci. 1991;11(1):203-9.

47. Mangan PS, Bertram EH 3rd. Shortened-duration GABA(A) receptor-mediated synaptic potentials underlie enhanced CA1 excitability in a chronic model of temporal lobe epilepsy. Neuroscience. 1997;80(4):1101-11.

48. Dougherty KA, Islam T, Johnston D. Intrinsic excitability of CA1 pyramidal neurones from the rat dorsal and ventral hippocampus. J Physiol. 2012;590(Pt 22):5707-22.

49. Honigsperger C, Marosi M, Murphy R, Storm JF. Dorsoventral differences in Kv7/M-current and its impact on resonance, temporal summation and excitability in rat hippocampal pyramidal cells. J Physiol. 2015;593(7):1551-80.

50. Lang M, Moradi-Chameh H, Zahid T, Gane J, Wu C, Valiante T, Zhang L. Regulating hippocampal hyperexcitability through GABAB Receptors. Physiol Rep. 2014;2(4):e00278.

51. Papatheodoropoulos C, Koniaris E. alpha5GABAA receptors regulate hippocampal sharp wave-ripple activity in vitro. Neuropharmacology. 2011;60(4):662-73.

52. Giannopoulos P, Papatheodoropoulos C. Effects of mu-opioid receptor modulation on the hippocampal network activity of sharp wave and ripples. Br J Pharmacol. 2013;168(5):1146-64.

53. Papatheodoropoulos C, Kostopoulos G. Spontaneous, low frequency (approximately $2-3 \mathrm{~Hz}$ ) field activity generated in rat ventral hippocampal slices perfused with normal medium. Brain Res Bull. 2002;57(2):187-93.

54. Patel J, Fujisawa S, Berenyi A, Royer S, Buzsaki G. Traveling theta waves along the entire septotemporal axis of the hippocampus. Neuron. 2012;75(3):410-7. 